\title{
PERCEPÇÕES DE ADOLESCENTES SOBRE SUA SEXUALIDADE
}

\author{
Kelly Ribeiro de Freitas ${ }^{1}$, Silvana Maria Zarth Dias²
}

\footnotetext{
${ }^{1}$ Enfermeira da Fundação Universitária Cardiologia do Rio Grande do Sul. Rio Grande do Sul, Brasil. E-mail: kelly.ufrgs@ gmail.com

2 Mestre em Enfermagem. Professora da Escola de Enfermagem da Universidade Federal do Rio Grande do Sul. Rio Grande do Sul, Brasil. E-mail: silvanazarth@ibest.com.br
}

RESUMO: O estudo qualitativo de natureza descritiva objetivou conhecer as percepções dos adolescentes sobre o desenvolvimento da sua sexualidade. Utilizou-se a abordagem do Método Criativo e Sensível que apresenta alternativa para pesquisa em enfermagem através da dinâmica grupal de "criatividade e sensibilidade". Participaram do estudo 12 adolescentes de uma escola estadual de Porto Alegre. Foram realizadas quatro dinâmicas para a coleta de informações. A análise respeitou as etapas do Método, contextualizado na pedagogia crítico-reflexiva proposta por Paulo Freire. Da análise emergiram três temas: o adolescente: vivenciando conflitos e dificuldades; a sexualidade para o adolescente; e o ato sexual. Considera-se importante destacar que as percepções dos adolescentes sobre sua sexualidade surgiram no âmbito dos debates e aliança de saberes durante as dinâmicas. Isso contribuiu para o estabelecimento de um novo ambiente de diálogo no contexto escolar que promoveu e facilitou o aprofundamento da temática, em linguagem acessível, e em parceria com os adolescentes.

DESCRITORES: Educação sexual. Educação em saúde. Sexualidade. Saúde do adolescente. Enfermagem.

\section{TEENAGERS' PERCEPTIONS REGARDING THEIR SEXUALITY}

\begin{abstract}
This qualitative study of a descriptive nature attempts to better understand the perceptions of teenagers regarding the development of their sexuality. The Creative and Sensitive Method approach, which presents an alternative to research in nursing through dynamic "creativity and sensitivity workshops" groups, was used. Twelve adolescents from a State School in Porto Alegre, RS, Brazil, participated in the study. Four workshops were held to collect information. The analysis respected the stages of the Method in the context of the Paulo Freire's critical-reflexive pedagogy. Three topics emerged from the analysis: the teenager: living conflicts and difficulties; sexuality for teenagers; and the sexual act. It is considered important to emphasize that the teenagers' perceptions regarding their sexuality emerged from the debates and the alliance to knowledge during the meetings. This contributed to establish a new environment for dialogue in the school context which promoted and helped the deepening of the subject in accessible language in partnership with the teenagers.
\end{abstract}

DESCRIPTORS: Sex education. Education in health. Sexuality. Teenager health. Nursing.

\section{LAS PERCEPCIONES DE LOS ADOLESCENTES SOBRE SU SEXUALIDAD}

RESUMEN: Es un estudio cualitativo de naturaleza descriptiva, con el objetivo de conocer las percepciones de los adolescentes sobre el desarrollo de su sexualidad. Se utilizó el enfoque del método creativo y sensible que presenta una alternativa a la investigación en enfermería a través de la dinámica de grupos de "creatividad y sensibilidad". Los participantes del estudio son 12 adolescentes de una escuela estatal de Porto Alegre. Para la recolección de los datos se hicieron cuatro talleres. El análisis siguió las etapas del método en el contexto de la pedagogía crítica de Paulo Freire. Tres temas emergieron del análisis: el adolescente: conflictos y dificultades de vida; la sexualidad para los adolescentes; y el acto sexual. Se considera importante hacer hincapié en que las percepciones de los adolescentes sobre su sexualidad surgieron en los debates y la alianza de conocimientos durante las reuniones, lo que contribuyó a la creación de un nuevo ambiente de diálogo en el contexto escolar que promovió y ayudó a la profundización del tema en un lenguaje accesible, en colaboración con los adolescentes.

DESCRIPTORES: Educación sexual. Educación em salud. Sexualidad. Salud de los adolescentes. Enfermería 


\section{INTRODUÇÃO}

A sexualidade é o desejo de contato, calor, carinho ou amor. Isso inclui olhar, beijar, autoprazer e produção de orgasmo mútuo. ${ }^{1}$ Aspecto central do ser humano, que abrange o ato sexual, as identidades, os papéis sociais, a orientação sexual, o erotismo, o prazer, a intimidade e a reprodução, a sexualidade também é percebida através dos pensamentos, fantasias, desejos, opiniões, atitudes, valores, comportamentos, práticas e nos relacionamentos. A interação dos fatores biológicos, psicológicos, sociais, econômicos, políticos, culturais, éticos, legais, históricos, religiosos e espirituais influenciam as práticas sexuais de cada grupo social. ${ }^{2}$ A sexualidade, pois, fenômeno da existência humana, presente na vida de adolescentes, é objeto de estudo e intervenção das políticas públicas, devido ao aumento dos índices de gravidez e incidência de aids entre os jovens. ${ }^{3}$

Nas ações práticas com adolescentes, no âmbito escolar, constatou-se, nas oficinas, nas consultas de enfermagem e nas conversas informais, que a temática de seu maior interesse era a sexualidade, a partir da descoberta da sua própria sexualidade, do desenvolvimento do seu corpo, dos relacionamentos, da formação de identidade, gênero e demais aspectos referentes ao tema. Nesses contatos, percebeu-se a falta de experiência e a resistência de alguns professores, pais ou responsáveis pelo adolescente, em conversar e explorar a temática. Essa resistência pode ser atribuída a questões educacionais, culturais, desconhecimento, insegurança, preconceitos, entre outros. Concorda-se que "o preparo para tratar das questões afetas à sexualidade tem pouco a ver com a formação acadêmica do educador e muito com a sua postura frente à vida e à sexualidade" ${ }^{4: 101}$ Crê-se que a escola, por seu papel fundamental na educação da criança e do adolescente, seja o espaço mais propício para os profissionais desenvolverem a sistematização desse conhecimento/aprendizagem. Crê-se, também, que a enfermagem deva utilizar esse espaço para desenvolver a educação em saúde, ampliando sua atuação nas escolas. Os enfermeiros, como profissionais de saúde com formação generalista, atuam nas diversas áreas, preventivas ou curativas, sendo que na educação em saúde, a saúde dos adolescentes constitui uma interface da sua atuação. ${ }^{5}$

Para tanto, é necessário buscar técnicas de abordagem adequadas, que estimulem o interesse dos escolares, em específico o dos adolescentes. A prática pedagógica de oficinas - forma eficiente de educação, construção do conhecimento e pensa- mento crítico para mudanças de comportamento - proporciona exposição de idéias, conceitos e experiências, para ambos, sem medo de qualquer julgamento. Esse fato possibilita transformar e aprimorar conceitos preconcebidos, através da reflexão sobre o tema, socialização de experiências e troca de saberes. Esse pressuposto gerou o objetivo deste estudo: conhecer as percepções dos adolescentes sobre o desenvolvimento da sua sexualidade.

\section{METODOLOGIA}

Este é um estudo qualitativo que se aplica ao estudo das relações, percepções e opiniões, produto das interpretações do modo de vida, do que se sente e se pensa, pois descreve, compreende explica a questão de investigação, aprofundando-se no mundo dos significados, crenças e valores dos sujeitos. ${ }^{6}$

Utilizou-se a abordagem do Método Criativo e Sensível (MCS), alternativa para pesquisa em enfermagem, através da dinâmica grupal de "dinâmicas de criatividade e sensibilidade", com produções artísticas e discussão grupal mediada pela pedagogia do método de ensino crítico-reflexivo de Paulo Freire. As dinâmicas foram codificadas pela elaboração das produções artísticas, decodificadas pelo diálogo grupal, que incluiu análise crítica e coletiva das produções artísticas e das ideias surgidas no grupo, e a discussão (troca de vivências entre os participantes). Das situações-problema representadas nas produções artísticas surgiram os temas, debatidos e recodificados sob forma de aliança de saberes. Esse momento, de aproximação e convergência de ideias, propiciou a síntese de cada tema discutido. A criação de espaço para diálogo livre, aberto e respeitoso possibilitou aos adolescentes a construção, reconstrução e a assimilação de novos conhecimentos e significados.

Realizou-se o estudo em uma escola do município de Porto Alegre-RS, com 12 alunos da sexta série do ensino fundamental, escolhidos intencionalmente, com idade entre 11 e 19 anos, previamente autorizados pelos responsáveis, e que aceitaram participar do estudo. A coleta das informações, realizada nas dinâmicas de criatividade e sensibilidade, respeitou as etapas propostas pelo MCS, e encerrouse com o término das dinâmicas propostas.

Realizaram-se dois encontros e quatro dinâmicas de criatividade e sensibilidade:

- Encontros: reunião para apresentação do projeto à direção da escola; reunião com os pais dos alunos, apresentando o projeto e solicitando, por escrito, a autorização para a participação dos 
filhos (Assinatura do Termo de Consentimento Livre Esclarecido).

$1^{a}$ dinâmica: apresentação da proposta de pesquisa, enfatizando-se o objetivo, o método criativo-sensível e a construção das regras de convivência. Para a atividade de codificação, cada participante fez um desenho a partir da questão norteadora; Como eu me vejo hoje?

$2^{\text {a }}$ dinâmica: os adolescentes elaboraram produções artísticas em resposta à questão norteadora O que significa sexualidade para mim? -, utilizando gravuras, figuras e frases de revistas representativas de suas percepções sobre sexualidade.

$3^{\text {a }}$ dinâmica: etapa da codificação. Os participantes elaboraram, por escrito, perguntas e dúvidas sobre sexualidade e as colocaram no "Saco-surpresa", a partir da questão: Minhas dúvidas sobre sexualidade. As perguntas foram respondidas com pesquisa em material bibliográfico.

$4^{a}$ dinâmica: revalidação da análise dos dados. Apresentou-se aos adolescentes a síntese das alianças de saberes de cada dinâmica e, em seguida, construiu-se a "Árvore de Saberes", em que cada adolescente escreveu o que lhe fora representativo.

A análise dos dados coletados obedeceu ao preconizado pelo MCS: codificação, decodificação e recodificação ou aliança de saberes ${ }^{7}$. As fases são: revisão de literatura e priorização dos problemas acerca da sexualidade; seleção dos tópicos centrais do estudo, trabalhados a partir das questões norteadoras, representados na forma de produção artística; codificação: produções artísticas que desvelaram os temas, por meio das falas dos adolescentes; decodificação: debate grupal onde os assuntos comuns foram ordenados e agrupados, estabelecendo os subtemas; exposição aos participantes dos temas e subtemas construídos nas oficinas, retificando as informações coletadas; e a construção da "Árvore de Saberes", que representa as considerações do grupo, na busca da convergência de idéias, compreensão de novos conhecimentos e validação das informações, estruturando a aliança de saberes.

O estudo foi aprovado pelo Comitê de Ética da Universidade Federal do Rio Grande do Sul (Protocolo $n^{\circ}$ 12604). Os participantes foram nomeados com um número, preservando-se, assim, suas identidades.

\section{CONHECENDO AS PERCEPÇÕES DOS ADOLESCENTES}

As dinâmicas permitiram aos adolescentes se expressarem, serem ouvidos e trocarem experiências, dando vozàs suas angústias e dúvidas, sem prejulgálos. Esses diálogos produziram os seguintes temas:

\section{Adolescente: vivenciando conflitos e difi- culdades}

O tema adolescente desvelou concepções e preocupações dos adolescentes sobre a formação de identidade, surgidas nas discussões de grupo das dinâmicas de criatividade e sensibilidade. As dinâmicas revelaram a necessidade de os participantes refletirem acerca de como é ser e sentir-se adolescente, momento propício para a introspecção e o autoconhecimento que envolve valores morais, pessoais e culturais de cada indivíduo.

O período de transição entre a fase infantil e adulta do ser humano faz com que o adolescente se depare com a perda da onipotência infantil, tornando-se um ser autocrítico na descoberta de seus defeitos. Entretanto, a sociedade atribui rótulos aos adolescentes - incapazes de pensar, de cuidar de si mesmos, de criar e atuar como sujeitos construtores de sua história. ${ }^{8}$ Muitos deles, inicialmente, durante as dinâmicas, percebiam-se sujeitos com defeitos, dizendo que eram chatos e tímidos e que não eram humildes. Porém, a contradição apareceu ao relatarem que, às vezes, eram legais, considerando importantes a amizade e a cumplicidade. A adolescência é, sem dúvida, a fase das contradições: o melhor e o pior; a aptidão física e a falta de jeito; a vivacidade psíquica e o insucesso escolar; o hedonismo e a desesperança; a arrogância e a falta de confiança. Talvez, a principal alteração da adolescência seja a modificação da percepção de si mesmo. ${ }^{9}$

A formação de grupos é outra característica importante que ocorre na adolescência. Pertencer ao grupo é importante e os adolescentes justificam suas atitudes para garantirem sua permanência nesse grupo. Essa característica serve de busca de sustentação dos adolescentes, individual e coletiva, formando o mundo de transição entre a independência e a autonomia. Embora a formação de grupos seja a busca de autoafirmação de identidade do adolescente, também faz parte desse contexto a timidez que o leva a refugiar-se, a ter atitudes agressivas, provocativas, no intuito de camuflá-la. ${ }^{9}$ Durante as dinâmicas, foram identificadas essas características de comportamento, típica dos adolescentes. Outro aspecto importante é a percepção do corpo como formador de identidade:

Tenho 11 anos e gosto do jeito que sou. Sou legal com minhas amigas. Sou uma pessoa um pouquinho gorda, eu tenho muitas farturas para dar e vender, porém eu 
acho que ninguémé melhor do que ninguém. Todo mundo é igual, mas eu me acho diferente dos outros (Aluno 9).

A maneira com que a pessoa se vê física e emocionalmente, e o modo com que é tratada pelo grupo ao qual pertence, na adolescência, tem grande importância e contribui para a formação de sua identidade adulta. A identidade sexual está mais vinculada à ideia de quem a pessoa acredita ser, e é formada, ao longo da vida, através da imagem física, do modo com que é tratada e se sente. ${ }^{8}$ Nesse contexto, a homossexualidade do adolescente é, muitas vezes, o resultado da curiosidade e do encontro entre duas pessoas que, por pertencerem ao mesmo gênero, têm problemas semelhantes. Durante as discussões grupais, os participantes referiram-se à homossexualidade sem demonstrar discriminação ou preconceito, embora tenham se referido a pessoas próximas - amigos, vizinhos - sem mencionar a própria escolha de identidade sexual.

Desenhei uma mulher querendo virar homem (Aluno 8).

Tenho um vizinho homossexual. Se veste como homem. Eu sei que é homossexual pelo jeito que ele anda, todo assim... (Aluno 4).

Homem com homem, mulher com mulher (Aluno 10).

Nesse contexto de lutas, conquistas, descobertas, formação de identidades, mudanças corporais, depara-se com uma turbulência de sensações inerentes a essa etapa da vida do ser humano. Durante as discussões, desvelaram-se características intrínsecas da adolescência, promovendo o autoconhecimento, indo além do objetivo proposto.

\section{A sexualidade para o adolescente}

No decorrer das dinâmicas, os adolescentes sentiram a necessidade de definir três termos: sexualidade, namoro e "ficar". Percebeu-se que os sujeitos da pesquisa tinham dificuldade de identificar suas percepções e sentimentos sobre sexualidade, não possuindo conceitos formados sobre os temas debatidos. Ao definir sexualidade, salientam a função reprodutora e de perpetuação da espécie. Sexualidade aparece como sinônimo de fazer sexo e sua definição é pautada na biologia dos corpos.

Sexo... entre duas pessoas (Aluno 2).

Sem sexo não ia ter reprodução (Aluno 5).

Fazer sexo. Porque senão a gente não seria seres humanos (Aluno 7).
Para alguns adolescentes, sexualidade significa amor, atração, paixão, algo inerente ao ser humano. Durante as discussões, surgiram os termos namorar e "ficar" como algo que faz parte da sexualidade. Entretanto, a reflexão sobre seus significados apareceu nos questionamentos: $\mathrm{O}$ que é namoro? Quando se está "ficando" há mais de três meses, é namoro? Namorar é fazer sexo?* Nesse contexto, entendeu-se que o "ficar" e o namorar são formas de relacionamento afetivo e íntimo entre duas pessoas e ambos dependem do tempo de seu relacionamento, da fidelidade dos atores envolvidos e da diferença de ter ou não relação sexual nesse relacionamento.

Para os adolescentes, "ficar" é:

[...] a primeira forma de relacionamento entre duas pessoas. O ficar é por um período curto e nenhuma das pessoas envolvidas necessita ser fiel. Todos concordaram dizendo que beijos e carícias fazem parte do ficar (Construção coletiva).

E namorar foi definido como:

[...] o segundo passo, depois do ficar, para a vida a dois. No namoro há um comprometimento entre duas pessoas, com a relação afetiva e intima por um tempo prolongado, sendo a fidelidade, fundamental. E que namorar não é fazer sexo, mas sexo faz parte do namoro (Construção coletiva).

Nas reflexões surgidas durante a dinâmica e a decodificação das produções artísticas, definir sexualidade tornou-se um desafio nas percepções dos adolescentes. Nas discussões promovidas no momento da recodificação, construiu-se o significado do termo sexualidade, contemplando seus anseios e interesses no contexto de sua vida:

Sexualidade não é só sexo com alguém, tem que ter carinho, beijo, abraço, tesão, atração e tem que ter conquista. É o amor entre duas pessoas. É o que diferencia os sexos, homem e mulher. Também é a gente escolher o sexo que a gente vai ter. É o jeito como nós nos vestimos, como escolhemos com quem vamos nos relacionar (Construção coletiva).

A sexualidade - o relacionar-se com outro - é influenciada fortemente pelas tecnologias, modificando os modos de aproximação. Os adolescentes procuram seu objeto sexual de maneiras diferenciadas. Atualmente, a primeira aproximação ocorre de forma objetiva, ou por influência do avanço tecnológico, facilitando esse momento:

A gente pede para ficar. Manda mensagem pela internet, MSN. Pelo celular, também (Aluno 4).

* Perguntas elaboradas pelos participantes na terceira oficina e colocadas no "Saco-surpresa". 
Entretanto, para os participantes, é importante ter sentimentos, afetividade e fidelidade envolvidos na procura do objeto sexual.

Já em relação à família, o diálogo sobre sexualidade e sexo ainda é tabu. Os adolescentes adquirem essas informações principalmente com amigos, revistas, filmes, televisão e internet, e poucas com professores e profissionais de saúde. Os pais transferem a responsabilidade da educação sexual para a escola, e a escola para os pais. ${ }^{9}$ Para os participantes das dinâmicas, o diálogo com os pais inexiste:

Não me ensinaram essas coisas ainda em casa (Aluno11).

A gente não conversa sobre esse assunto em casa com os pais (Aluno 6).

Os pais são, pela ordem natural, os primeiros educadores, o alicerce da educação dos filhos, mas não são seres completos. Nesse contexto, a escola e o Estado devem caminhar juntos em busca de uma educação que contemple essa temática na sua transversalidade. ${ }^{9}$ É importante que os pais não deleguem a outros a tarefa de falar com os filhos sobre sexo. Também é fundamental saber qual a forma mais adequada para abordar o assunto, especialmente com adolescentes, ${ }^{10}$ pois sabe-se que grande parte do conhecimento dos adolescentes sobre sexo é adquirida de seus pares, da televisão, de filmes e de revistas. ${ }^{11}$

\section{$\mathrm{O}$ ato sexual}

Os participantes manifestaram curiosidade sobre aspectos relacionados à idade certa para iniciação sexual, à idade que a mulher está com maturidade fértil, ao comportamento e atitudes de homens e mulheres na primeira relação sexual e sobre a autonomia da decisão de ter a relação sexual. Deduz-se essa curiosidade das perguntas e dos discursos apresentados: Se a menina não menstruar até os 13 anos de idade ela pode ter relação sexual? Que idade a mulher começa a gerar? Como a pessoa age na primeira vez?**

Para as gerações jovens atuais, a conquista da independência é cada vez mais tardia, o que não impede que a autonomia da sexualidade seja uma aspiração cada vez mais precoce, e esse paradoxo forja a construção social da adolescência na contemporaneidade, tornando as relações entre gerações mais complexas..$^{12} \mathrm{O}$ processo de construção da identidade adulta, na adolescência, atualmente, implica iniciação sexual dos jovens, embora eles não tenham o entendimento necessário para se relacionarem sexualmente. Ao mesmo tempo, o desenvolvimento dos caracteres sexuais primáriose secundários e a sensibilidade aumentada dos órgãos genitais produzem pensamentos e fantasias a respeito das relações sexuais ${ }^{10}$. No decorrer das dinâmicas, os adolescentes apresentaram curiosidade sobre as formas de fazer sexo. O que é sexo oral? A gente engravida fazendo sexo anal? A gosma do homem pode engravidar? ${ }^{* * *}$ Cabe, portanto, aos enfermeiros, refletirem, juntamente com os adolescentes, sobre a importância e a naturalidade de descobrir o seu corpo, desmitificando o ato sexual.

Observam-se, na atualidade, mudanças relacionadas ao comportamento sexual dos adolescentes, como por exemplo, a redução da idade em que iniciam as relações sexuais.

Nas últimas décadas, no mundo, a repetição da parentalidade na adolescência tem aumentado, porém, esta fica mais evidente nos países emergentes, tendo em vista a pouca escolaridade, a falta de informação, a desagregação familiar e a instabilidade econômica, especialmente nos adolescentes de nível socioeconômico mais baixo. ${ }^{13}$ Essas alterações de comportamento acarretam aumento do número de gravidez, abortos e doenças sexualmente transmissíveis na adolescência.

Salienta-se que os adolescentes têm direito ao sigilo sobre sua atividade sexual e ao acesso gratuito aos métodos contraceptivos. A consciência desse direito implica reconhecer a individualidade do adolescente, estimulando a responsabilidade com sua própria saúde. ${ }^{8}$ Tornar os jovens responsáveis pela sua saúde é uma forma de estimular a independência e a autonomia para que caminhem lado a lado com a construção de suas identidades.

Nas questões apresentadas pelos participantes, deparou-se com as preocupações dos adolescentes em relação à prevenção de Doenças Sexualmente Transmissíveis (DST) e gravidez na adolescência, expressas nos questionamentos: Como é a camisinha de mulher? Como se pega doença através do beijo? Se o homem e a mulher usarem camisinha, é mais seguro? Como se usa camisinha feminina? A doença pega mais no homem ou na mulher? Como se pega doença através do sexo? Pode ficar grávida na primeira vez? Observou-se que muitos jovens julgam menos embaraçoso ter relações sexuais do que se prepararem com contraceptivos para o ato

\footnotetext{
** Perguntas elaboradas pelos participantes na terceira dinâmica e colocadas no "Saco-surpresa". *** Perguntas elaboradas pelos participantes na terceira dinâmica e colocadas no "Saco-surpresa".
} 
sexual. ${ }^{9}$ Essa problemática e a questão da submissão feminina influenciam os fatores de risco de vulnerabilidade que expõem os adolescentes às DST/HIV/ aids. ${ }^{14}$ Destacamos que a gravidez na adolescência ou ocorrência de DST ainda pode ser fruto da falta de informação sobre saúde reprodutiva e métodos contraceptivos. A timidez do adolescente e a falta de intimidade com o parceiro para negociar o uso de preservativo pode interferir na tomada de decisão. Por sua vez, a gravidez reflete-se na busca da autonomia e independência do adolescente para conquistar seu espaço no mundo adulto.

\section{CONSIDERAÇÕES FINAIS}

Buscou-se, aqui, conhecer as percepções dos adolescentes sobre o desenvolvimento da sua sexualidade e contribuir para o crescimento dos saberes que estruturam o ensino da educação em saúde voltado para esses sujeitos. Os adolescentes revelaram que seus interesses em relação à sexualidade estão ligados à afetividade e à busca de um parceiro, ou seja, à procura do objeto sexual, ainda que relatem preocupação com a prevenção de DST e gravidez na adolescência. Eles ressaltaram, ainda, os conflitos que vivenciam nessa fase, como um momento de transição, marcado pelas conquistas próprias da adolescência.

O tema "O ser adolescente: vivenciando conflitos e dificuldades" desvelou aspectos importantes para os adolescentes no processo de construção da identidade adulta. O primeiro deles foi a autocrítica, por vezes distorcida ou influenciada por conceitos culturais, na qual se veem como pessoas com defeitos. Uma explicação para isso pode ser o preconceito dos adultos que, muitas vezes, rotulam os adolescentes como "aborrescentes", atribuindo-lhes incapacidade de pensar, de cuidar de si mesmos, de criar e atuar como sujeitos construtores. É importante destacar a fascinação pela conquista de liberdade e autonomia nessa fase de transição. Embora alguns adolescentes digam ser crianças, essa fase é marcada por não quererem ser tratados como tal e desejarem a independência de um adulto. Há, na verdade, a crise de identidade, em que a certeza passa pela dúvida, ou seja, querem mostrar que já não são crianças, ultrapassando os limites impostos pelos adultos. Outro aspecto importante, presente nos diálogos dos adolescentes, foi a formação de grupos que lhes servem de busca para a sua autoafirmação, de modo individual e coletivo, e enfatizam a importância da amizade sincera e verdadeira. A timidez também aparece, proporcionando o autoconhecimento e a consciência crítica de suas atitudes.
Os adolescentes manifestaram preocupação com sua imagem corporal. A construção da identidade sexual e as mudanças corporais fazem com que se estabeleçam distinções entre feminilidades e masculinidades, refletindo-se em transformações na formação dos sujeitos. A homossexualidade foi abordada de forma natural, e os adolescentes demonstraram compreensão e respeito pela opção sexual do ser humano. Os participantes enfatizaram que a aparência física, os trejeitos e o modo de vestir revelam a escolha de uma identidade sexual, embora pensar e falar sobre a sua identidade sexual lhes tenha sido mais difícil.

No tema "A sexualidade para o adolescente" percebeu-se que os jovens de hoje têm facilidade de acesso à informação e ao conhecimento, através de diferentes fontes: internet, livros, revistas; porém, continua sendo indispensável o diálogo e a discussão com pessoas capacitadas e disponíveis para esclarecê-los e ajudá-los no entendimento de sua sexualidade. Por isso, fez-se necessária a construção de alguns conceitos - "ficar", namorar e sexualidade - durante as alianças de saberes nas dinâmicas de criatividade e sensibilidade. Para viver sua sexualidade plena, os jovens apontaram a confiança no parceiro e a segurança nas atitudes relativas aos relacionamentos e na relação sexual. Mostraram-se preocupados com seu preparo para realizar o ato sexual e obter informações, conhecimento e entendimento sobre sexo e sexualidade, prevenindo-se, assim, de possíveis arrependimentos. Na busca do objeto sexual, os adolescentes consideram que se deve ter amor, carinho, intimidade, respeito, entusiasmo e paixão sincera entre duas pessoas. Desse discurso pode-se inferir a importância da fidelidade nas relações afetivas, pois, em nenhum momento, referiram-se a mais de duas pessoas na relação amorosa e sexual.

A educação sexual deve envolver vários aspectos da evolução psíquica do adolescente. É relevante que o profissional ou a pessoa que irá abordar essa temática tenha ciência dos processos evolutivos e conflitivos que envolvem a adolescência e seja desprovido de preconceitos e prejulgamentos, atuando como mediador nas discussões sobre a sexualidade, construindo, em parceria com os adolescentes, alternativas e formação de opiniões coerentes com a realidade de cada um deles. É importante ressaltar que a educação sexual deve ser abordada pela escola, em conjunto com a família e a rede de saúde e educação. Todos devem ter uma mesma linguagem e preocupação com a transversalidade dessa temática. 
O tema "O ato sexual" apontou para as consequências de seus atos. $\mathrm{O}$ uso de preservativos na prevenção de doenças e da gravidez, associado ao estar saudável para construir uma vida afetiva, reflete-se no cotidiano dos adolescentes. Evidenciaram-se, no debate grupal, inúmeras dúvidas dos adolescentes sobre o seu agir enquanto sujeitos dos relacionamentos e sobre a hora certa da primeira relação sexual. Muitas vezes, sentem-se tímidos, e a falta de intimidade com o parceiro, para negociar o uso de preservativo, pode interferir na tomada de decisão pelo uso de camisinha. É importante ressaltar que não se deve ter a pretensão de mostrar os caminhos e as estratégias que minimizem suas dúvidas, mas deve-se problematizar o tema com os adolescentes, para que busquem alternativas responsáveis e coerentes com seus interesses.

Os adolescentes relataram que foi a primeira vez que tiveram oportunidade de ser escutados e que eles sentiram-se à vontade para falar; que haviam participado de palestras monótonas no posto de saúde e que somente os palestrantes falaram, sem que pudessem expor dúvidas.

Assim, acreditamos que o MCS mostrouse uma estratégia metodológica importante que permitiu mergulhar no mundo dos adolescentes, conhecendo suas percepções e concepções acerca da sua sexualidade. Compartilhar as expressões, a construção e a reconstrução havidas por meio das produções artísticas e dos diálogos, desvelou o que permaneceu oculto por muito tempo.

Acredita-se que este estudo contribuiu para o processo de conhecimento dos adolescentes sobre sua sexualidade, o que favorece a emancipação do sujeito e promove o autocuidado. Ressalta-se a importância de construir uma consciência crítica que leve os participantes a pensar sobre a formação de suas identidades.

\section{REFERÊNCIAS}

1. Stuar GW, Laraia MT. Enfermagem psiquiátrica princípios e prática. $6^{\mathrm{a}}$ ed. Porto Alegre (RS): Artmed; 2001.

2. World Health Organization (OMS). Glossary [online]. Genebra (SZ): World Health Organization; 2002 [acesso 2007 Mai 14]. Disponível em http://www.who. int/reproductive-health/gender/glossary.html.
3. Maheirie K, Urnau LC, Vavassori MB, Orlandi $\mathrm{R}$, Baierle RE. Oficinas sobre sexualidade com adolescentes: relato de experiência. Psicologia em estudo. 2005 Set-Dez; 10(3):537-42.

4. Oliveira DL. Sexo e saúde na escola: isto não é coisa de médico? In: Meyer DE, Dalla Zen MI, Xavier MLF, organizadora. Saúde e sexualidade na escola. Porto Alegre (RS): Mediação; 2006. p 97-109

5. Oliveira TC, Carvalho LP, Silva MA. O enfermeiro na atenção à saúde sexual e reprodutiva dos adolescentes. Rev Bras Enferm. 2008 Jun [acesso 2010 Abr 14]; 61(3): Disponivel em: http://www. scielo.br/scielo.php?script=sci_arttext\&pid=S003471672008000300005\&lng=en\&nrm=iso

6. Minayo MCS. O desafio do conhecimento: pesquisa qualitativa em saúde. $9^{a}$ ed. São Paulo (SP): Hucitec; 2006.

7. Cabral IE. Aliança de saberes no cuidado e estimulação da criança bebê. Rio de Janeiro (RJ): Editora da Escola de Enfermagem Ana Nery; 1999.

8. Ministério da Saúde (BR). Saúde e prevenção nas escolas: guia para formação de profissionais. Secretaria de Vigilância em Saúde. Brasília (DF); 2006.

9. Almeida JMR. Adolescência e maternidade. $2^{\mathrm{a}}$ ed. Lisboa (PT): Fundação Calouste Gulbenkian; 2003.

10. Zagury T. Os direitos dos pais: construindo cidadãos em tempos de crise. $8^{\mathrm{a}}$ ed. Rio de Janeiro (RJ): Record; 2004.

11. Winkelstein, ML, Wilson D, Hockenberry MJ. Wong: fundamentos de enfermagem pediátrica. $7^{\mathrm{a}} \mathrm{ed}$. Rio de Janeiro (RJ): Elsevier; 2006.

12. Brandão ER, Heilborn ML. Sexualidade e gravidez na adolescência entre jovens de camadas médias do Rio de Janeiro. Cad Saúde Pública. 2006 Abr [acesso 2007 Fev 07]; 22(7): Disponível em: http://www. scielo.br/scielo.php?script=sci_arttext\&pid=S0102311X2006000700007

13. Carvalho GM, Merighi MAB, Jesus MCP. Recorrência da parentalidade na adolescência na perspectiva dos sujeitos envolvidos. Texto Contexto Enferm. 2009 Mar [acesso 2010 Abr 14]; 18(1): Disponível em: http:/ / www.scielo.br/scielo.php?script=sciarttex t\&pid=S01047072009000100002\&lng=pt\&nrm=iso

14. Torres CA, Barbosa SM, Barroso MG, Pinheiro PNC. Investigando a vulnerabilidade e os riscos dos adolescentes em meio as DST/HIV/AIDS nos seus diversos contextos- um estudo exploratório. Online Braz J Nurs. 2008 Abr [acesso 2008 Jul 09]; 7(1): Disponível em: http:/ / www.uff.br/objnursing/index.php/ nursing/article/view/j.1676-4285.2008.1138/292 